\title{
Medicolegal Aspects of Craniofacial Trauma
}

\author{
Nima Vahidi, MD ${ }^{1}$ Weitao Wang, MD ${ }^{20}$ Thomas Lee, MD, FACS ${ }^{1}$ Jared Inman, MD, FACS 3 \\ Yadranko Ducic, MD, FRCS(C), FACS ${ }^{2}$
}

${ }^{1}$ Department of Otolaryngology-Head and Neck Surgery, Virginia

Commonwealth University Medical Center, Richmond, Virginia

${ }^{2}$ Otolaryngology and Facial Plastic Surgery Associates,

Fort Worth, Texas

${ }^{3}$ Department of Otolaryngology-Head and Neck Surgery,

Loma Linda University, Loma Linda, California

\author{
Address for correspondence Yadranko Ducic, MD, FRCS(C), FACS, \\ Department of Otolaryngology and Facial Plastic Surgery, \\ Otolaryngology and Facial Plastic Surgery Associates, 923 \\ Pennsylvania Avenue, Suite 100, Fort Worth, TX 76104 \\ (e-mail: yducic@sbcglobal.net).
}

Facial Plast Surg 2019;35:657-665.

\begin{abstract}
Keywords

- medicolegal

- craniofacial trauma

- facial plastic surgery

- medical malpractice

Characterization of complications in facial trauma management is of special interest to practitioners of facial trauma surgery. It is important for facial trauma surgeons to not only understand the standard of care, but also the pitfalls that can expose them to litigation. Litigation within the realm of facial trauma surgery often manifests from issues with poor communication, inadequate informed consent processes, and poor surgical management. In this analysis, we comprehensively examine malpractice litigation in facial trauma surgery, and outline important factors for surgeons to consider in the care of this patient population. It is important for facial trauma surgeons to understand medicolegal issues within their scope of practice. These include principles of informed consent, state regulated statutes of limitation, and Emergency Medical Treatment and Active Labor Act laws. This analysis emphasizes the importance of exercising appropriate patient care, understanding the indications for surgery, and seeking counsel when necessary.
\end{abstract}

Medical malpractice lawsuits have been on the rise in recent decades and have unfortunately become an influential factor in dictating the way we practice medicine today. There has been an increase in the practice of defensive medicine, and a greater hesitancy to treat perceived high-risk patients. It is estimated that the direct cost associated with malpractice litigation is between $\$ 7$ and $\$ 10$ billion dollars per year for health care providers. In the vast majority of medical malpractice lawsuits, the basis for the claim stems from a dispute over the quality of care provided. ${ }^{1,2}$

There has been a significant effort in recent years to improve the quality of health care services in the United States. Despite this effort, medical errors rates continue to exceed those of other industries. Malpractice cases continue to account for a substantial expense of time, money, and energy in the health-care industry.

Our analysis provides an in-depth characterization of medicolegal issues surrounding the field of craniofacial trauma. Although the main focus of this analysis is for medical providers caring for facial trauma patients, many of the principles outlined here may also apply to practitioners in other specialties.

\section{Medical Malpractice}

Medical malpractice is defined as an act or omission by a medical professional that deviates from acceptable medical care, thereby causing injury to a patient. Typically, four conditions must be met in order for a claim to be classified as a medical malpractice and ultimately award subsequent payment. These conditions are (1) a presence of duty to act, (2) a breach of duty, (3) harm experienced by the patient, and (4) evidence of direct causation. ${ }^{3}$

An adverse outcome that directly resulted from a physician's actions is not sufficient enough for awarding damages to a plaintiff. Additionally, openly discussing medical errors, complications, and deaths in a medical setting does not increase the risk of lawsuit. ${ }^{4}$ In situations where surgical complications have occurred, it is important to maintain transparency and keep an open line of communication. It is
Issue Theme Contemporary Management of Facial Trauma and Complications; Guest Editor: Yadranko Ducic, MD, FRCS(C), FACS
Copyright (C) 2019 by Thieme Medical Publishers, Inc., 333 Seventh Avenue, New York, NY 10001, USA. Tel: +1(212) 584-4662.
DOI https://doi.org/ 10.1055/s-0039-1700798. ISSN 0736-6825. 
the physician's responsibility to maintain trust and guide the patient and family through the process of addressing the complication that has occurred, and the process moving forward. Additionally, it is extremely important to maintain constant communication between all medical providing teams as to avoid misunderstandings or confusion on the patient's part. Patients are much less likely to pursue litigation if they trust their clinical providers.

There is evidence to show that physician concerns surrounding malpractice insurance and litigation have prompted physicians to avoid high-risk specialties, leave states perceived as high risk, and even avoid providing charity care. ${ }^{5,6}$ Physicians, specifically surgeons in any specialty, can minimize liability in several ways including executing a detailed informed consent process, and creating open dialogue with patients regarding expectations. ${ }^{2,4}$

\section{Informed Consent Process}

Informed consent was first introduced in 1957 and mandated that a patient must receive sufficient information before consenting to a medical procedure. Today the informed consent process has been further expanded to involve an explanation by the physician of the information that a patient requires to make a knowledgeable decision regarding a recommended course of medical or surgical intervention. Physicians have a legal and moral obligation to disclose specific information during the informed consent process including the nature and purpose of the treatment, the benefits and potential risks, the consequence of not receiving treatment, and any alternative therapies available. ${ }^{7}$

It is always best for the operating surgeon to be directly involved in the consenting process and also establish an ongoing open dialogue with the patient. Additionally, of importance is that patients' recall of information is best immediately after signing a consent document, but that the recall rate steadily declines with time. Therefore, information should always be reiterated at the time of surgery to avoid any misunderstanding or confusion. Recent studies have also shown that providing written information may provide a necessary reinforcement of the verbal dialogue and improve overall understanding and recall of the treatment procedure and complications. Additionally, written material has been shown to reduce anxiety in patients undergoing surgery, and ultimately improve patient satisfaction with their treatment. ${ }^{7}$

The readability of the information and the informed consent has been a topic of study in the literature as well. Several US organizations have pushed for the readability of health care materials to be no higher than that of the sixthgrade level, or what is expected of an 11-year-old child. ${ }^{8}$ While concerns regarding the readability of the informed consent are legitimate, ultimately the two-way conversation remains the cornerstone of the informed consent process.

\section{Practicing Defensive Medicine}

Defensive medicine is defined as medical practices carried out primarily to avoid malpractice liability rather than to benefit the patient. In the United States, it is estimated that the annual cost attributed to defensive medicine is roughly $\$ 50$ billion. Certain specialties, such as emergency medicine, general surgery, and neurosurgery, may be more prone to the practice of defensive medicine. For a facial trauma surgeon, these practices can include obtaining unnecessary maxillofacial scans, prescribing unwarranted antibiotics, and even an avoidance to surgically treat patients. ${ }^{6,9}$ Historically, there has always been a perceived high malpractice risk for the treatment of trauma patients despite studies demonstrating no increased risk of lawsuit when caring for trauma patients. $^{10}$

\section{Litigation in Facial Plastic Surgery}

In comparison to physicians from other specialties, plastic surgeons have a higher lifetime risk of malpractice litigation. In the United States nearly $15 \%$ of all plastic surgeons face one malpractice claim annually. Although it can be difficult to elucidate the exact cause of these lawsuits, studies have shown that the majority of litigation cases against plastic surgeon surround issues of incomplete consent, poor cosmetic result, excess scarring, and lack of expertise in performing a given procedure. $^{3,11,12}$

Svider et al published a retrospective review specifically looking at litigation issues as they relate to a facial plastic surgeon between 1984 and 2012. They showed that of the lawsuits that involved a facial plastic surgeon, $62.5 \%$ were decided in the physician's favor, 9.1\% were resolved with a settlement, and $28.4 \%$ resulted in a jury awarding damages for malpractice. The mean settlement was found to be $\$ 577,437$ and the mean jury award was $\$ 352,341$. The most commonly litigated facial plastic surgery procedures were blepharoplasties and rhinoplasties. However, the most commonly litigated cases that resulted in payment were repair of cleft deformities and facial fracture repair. They found that the most common complaints leading to litigation were excessive scarring/disfigurement, difficulty with eye closure, and postoperative pain. A lack of informed consent was noted to be the most common factor (38.6\%) resulting in litigation. Additionally, the study found that there was increased incidence of litigation in California and Florida as compared to other states. ${ }^{3,13}$

Another common target for litigation in the field of facial plastic surgery is cranial nerve $(\mathrm{CN})$ injuries due to their lasting functional outcomes. The most commonly litigated cranial nerves are CN VII (facial nerve) and CN II (optic nerve). The literature shows that nearly one-third of lawsuits citing a $\mathrm{CN}$ injury result in damages awarded. Average damages awarded for $\mathrm{CN}$ injuries are nearly $\$ 2$ million. The most commonly named problems were a deficit in informed consent, performing unnecessary procedures, the need for additional surgery, and not recognizing and addressing complications adequately. ${ }^{11}$ Svider et al described that the primary issue in most cases of litigation with informed consent was not that the physician failed to discuss the possibility of adverse outcomes, but rather that they failed to clearly stated the specific complications that could occur. ${ }^{3}$ 
Thus, it is important to inform patients of the potential for temporary or permanent facial nerve injury when working in the preauricular region (i.e., mastoidectomy, parotid surgery, and open subcondylar mandible fracture repair). Additionally, when operating in the periorbital region (i.e., orbital floor repair, naso-orbitoethmoid (NOE) fracture repair, anterior skull base surgery, and open frontal sinus repair), the risk of potential for temporary or permanent vision change, blindness, diplopia, and injury to extraocular muscles deserves mention.

Within the scope of facial plastic surgery, cosmetic procedures, such as the placement of implants and fillers, are another area of exposure for potential litigation. Studies have shown that the most common complications of implantable materials are infection, migration, swelling, and extrusion. A lack of awareness of the potential complications by the patient can open physicians up to lawsuits. For implantable materials studies have shown that most complications occur within the first 60 days, and therefore close monitoring of patients during this time may aid in improving long-term clinical outcomes and avoiding potentially treatable complications. Similarly, within the field of facial implants, the most commonly cited factors for litigation include inadequate informed consent and the need for additional surgical intervention. $^{14-16}$

\section{Guidelines for Facial Trauma Treatment}

A proper facial trauma evaluation begins in the preoperative stage with a thorough history and physical examination. During the primary survey (initial assessment), airway, breathing, circulation, and mental status are assessed along with any immediately life-threatening injuries (-Table $\mathbf{1}$ ). This proceeds a formal evaluation of any facial injuries. In Tung et al's review of 1,025 patients with facial fractures it was found that $1.7 \%$ required immediate airway intervention and $6.2 \%$ had life-threatening injuries requiring immediate intervention in the emergency room (i.e., chest tube place- ment, craniotomy, and massive blood transfusion). ${ }^{17}$ Careful documentation and timing of events should be performed during this stage.

During the secondary survey, focused history and physical examination is performed. It is important at this time to rule out cervical spine fractures and carotid/vertebral injuries as these injuries can be common in facial trauma patients. ${ }^{18}$ Mulligan et al analyzed the National Trauma Data Bank involving 2.6 million patients from 2002 to 2006 and found concurrent facial fractures in $13.5 \%$ of combined cervical spine injury patients, $21.7 \%$ of head injury patients, and $24 \%$ of combined cervical spine and head trauma patients. ${ }^{19}$ The presence of carotid artery or vertebral artery injury may lead to delaying facial fracture repair as these patients have a high risk of neurologic morbidity (60\%) and mortality (19$43 \%){ }^{20-23}$ In situations where carotid or vertebral artery injuries are present, neurosurgery or vascular surgery consult with documentation of surgical clearance prior to facial fracture repair would be wise. The presence of cervical spine fractures requires immobilization of the cervical spine intraoperatively, which can increase the difficulty of the surgery and should be considered beforehand. Similarly, surgical clearance from the spine surgery team, with documentation of the potential risks (i.e., stroke and temporary or permanent neurologic deficits) should be obtained for patients with suspected cervical spine injuries prior to facial fracture repair.

Only after the primary and secondary surveys have been completed and the patient considered stable is it appropriate to perform a full head and neck examination. The head and neck examination should be performed with a particular focus on $\mathrm{CN}$ findings (-Table 2), ocular examination (-Table 3), and dental occlusion. Photographic documentation of all facial injuries may also provide useful information for medicolegal reasons.

In instances during which a patient cannot provide a reliable examination due to mental status changes or intubation, it may be beneficial to delay facial fracture repair

Table 1 Primary survey in trauma evaluation

\begin{tabular}{|c|c|}
\hline \multicolumn{2}{|c|}{ Primary trauma survey } \\
\hline \multicolumn{2}{|l|}{ Airway } \\
\hline & $\begin{array}{l}\square \text { Confirm airway is protected } \\
\text { - Rule out oral or upper airway swelling or bleeding with potential for immediate airway compromise } \\
\text { - Patients with compromised mental status may need airway protection } \\
\text { - If cervical spine injury is suspected, avoid hyperextending the neck during intubation/airway management } \\
\text { - If there is concern for laryngotracheal dissociation, do not attempt oral intubation. Instead consider } \\
\text { tracheostomy placement }\end{array}$ \\
\hline \multicolumn{2}{|c|}{ Breathing } \\
\hline & $\begin{array}{l}\square \text { Listen for bilateral breath sounds } \\
\square \text { Symmetric chest wall motion, midline trachea }\end{array}$ \\
\hline \multicolumn{2}{|c|}{ Circulation } \\
\hline & $\begin{array}{l}\square \text { Check pulses and blood pressure } \\
\square \text { Establish vascular assess } \\
\square \text { Stop visual hemorrhage } \\
\square \text { Determine need for Intravenous fluids or blood products }\end{array}$ \\
\hline
\end{tabular}


Table 2 Cranial nerve examination

\begin{tabular}{|c|c|}
\hline \multicolumn{2}{|c|}{ Cranial nerve examination } \\
\hline I & $\square$ Sense of smell \\
\hline II & $\square$ Visual acuity, color, visual fields, pupil response \\
\hline III & $\square$ Extraocular movements, pupil response \\
\hline IV & $\begin{array}{l}\square \text { Turn eye downward and laterally } \\
\text { - Deficit could indicate superior oblique } \\
\text { muscle palsy }\end{array}$ \\
\hline $\mathrm{V}$ & $\begin{array}{l}\square \text { Sensation along forehead (V1), midface (V2), } \\
\text { and mandible (V3) }\end{array}$ \\
\hline $\mathrm{VI}$ & $\begin{array}{l}\square \text { Lateral eye movement } \\
\text { - Deficit could indicate lateral rectus muscle palsy }\end{array}$ \\
\hline VII & $\begin{array}{l}\square \text { Symmetry of face (House-Brackmann Scale I-VI) } \\
\text { - Temporal branch: raise eyebrows, frown } \\
\text { - Zygomatic branch: close eyes tightly } \\
\text { - Buccal branch: smile or show teeth with } \\
\text { upper lip movement } \\
\text { - Buccal branch: puff out cheeks } \\
\text { - Marginal mandibular branch: smile } \\
\text { with lower lip depression }\end{array}$ \\
\hline VIII & $\begin{array}{l}\square \text { Auditory (tuning fork test) } \\
\square \text { Vestibular (nystagmus on lateral gaze) }\end{array}$ \\
\hline IX & $\square$ Taste, gag reflex \\
\hline$x$ & $\square$ Hoarseness, vocal cord mobility, gag reflex \\
\hline $\mathrm{XI}$ & $\begin{array}{l}\square \text { Shrug shoulders (trapezius muscle) } \\
\square \text { Turn head against pressure } \\
\text { (sternocleidomastoid muscle) }\end{array}$ \\
\hline XII & $\square$ Stick out tongue, move it side to side \\
\hline
\end{tabular}

until such examination can be obtained. Consideration should be made that bony fusion of facial fractures may occur within a 2-week time frame. Injuries, such as traumatic optic neuropathy or retinal detachment, can occur without radiological evidence and would be difficult to delineate without an appropriate examination. If such patient undergoes periorbital surgery, and postoperatively endorses vision loss, it would be difficult to determine if the surgery or the initial accident was the ultimate cause. To minimize legal liability, delaying facial fracture repair until appropriate $\mathrm{CN}$ or vision examination can be obtained may prove beneficial for patient counseling.

Facial nerve or soft tissue injuries of the face can have a profound impact on trauma patients both from a functional and cosmetic standpoint. While an in-depth discussion of management of facial nerve repair/reconstruction and soft tissue injuries of the face is beyond the scope of this article, key wound care principles should be adhered to including an attempt at facial nerve repair if deemed appropriate. ${ }^{24}$ This may require consultation with a facial nerve surgery specialist as the best functional recovery is typically seen with facial nerve repair at the time of injury. The patient and family should be counseled and supported throughout this process, and a discussion of the need for future surgery should be had early in the treatment course.

In situations where there is a concern for a bony fracture, a high-resolution computerized tomography (CT)-maxillofa- cial scan should be obtained with $1 \mathrm{~mm}$ or less thickness. The scan should assess axial, coronal, and sagittal views. For complex, pan-facial fractures, a three-dimensional reconstruction of the CT scan can be helpful for operative planning. Any fractures involving the mandible may also benefit from panorex as it may have less dental or metal artifacts when compared to a CT scan and provides additional views of the mandible and dental roots. During the intraoperative stage, the patient may benefit from preincision dose of intravenous antibiotics. $^{25}$

In the immediate postoperative stage, an assessment of visual acuity and $\mathrm{CN}$ function should be made. Prophylactic antibiotics may be continued up to 24 hours after the surgery, although the current literature does not show a significant benefit beyond this point. ${ }^{26}$ If an intraoperative CT scan was not obtained, a postoperative CT scan may be useful in assessing proper bony reduction and proper hardware placement, and to ensure all the fractures have been properly treated ( $\mathbf{- T a b l e s} \mathbf{1}, \mathbf{3}$, and $\mathbf{4}){ }^{26}$

\section{Ophthalmologic Evaluation in Facial Trauma}

As mentioned previously, vision loss is one of the most common cited factors in litigation. ${ }^{11}$ Fifteen percent to $20 \%$ of patients with major facial trauma suffer vision-threatening injuries. ${ }^{27}$ Early identification and prompt management of ophthalmologic injuries results in a better overall prognosis. Facial trauma surgeons should be comfortable with the proper ophthalmologic examination as well as immediate vision-saving procedures (i.e., lateral canthotomy in the setting of expanding orbital hematomas). ${ }^{28}$ It is important when dealing with ophthalmic injuries to properly document timing of injuries, procedures, etc., as optic nerve injuries are a time-sensitive matter. ${ }^{29}$

Initial preoperative examination should include visual acuity, pupillary function, color perception, and integrity of extraocular muscle movements. If any abnormalities are noted, a more detailed ophthalmologic examination is warranted which includes fundoscopic examination, intraocular pressure, and retinal assessments.

It is important to note that most instances of traumatic optic neuropathy (80\%) occur in the absence of optic canal fracture. ${ }^{30}$ In the traumatic setting, sudden deceleration and traction injury to the optic nerve which is fixated to the underlying periosteum may cause vision loss. Trauma to the lateral brow, mid glabella, and occiput may result in posttraumatic optic neuropathy; therefore, particular attention should be paid when assessing these areas. The red-color desaturation is the most sensitive indicator of posttraumatic optic neuropathy during the initial trauma examination. ${ }^{27,28}$ Studies have shown that in patients with posttraumatic optic neuropathy 20 to $50 \%$ may have spontaneous improvement in vision. ${ }^{31}$ The data regarding posttraumatic optic neuropathy is limited at best, and there is currently no clearly accepted algorithm in the treatment process. Some studies have shown improvement in vision with medical therapies such as corticosteroids and head-ofbed elevation. Surgical interventions, such as optic canal 
Table 3 Ophthalmologic evaluation of a facial trauma patient

\begin{tabular}{|c|c|}
\hline \multicolumn{2}{|c|}{ Ophthalmologic examination } \\
\hline \multicolumn{2}{|c|}{ External examination } \\
\hline & $\square$ Gross inspection of the eye and ocular adnexa \\
\hline \multicolumn{2}{|c|}{ Penlight examination } \\
\hline & $\square$ Assessment of the conjunctiva, cornea, anterior chamber, and lens \\
\hline \multicolumn{2}{|c|}{ Pupil evaluation } \\
\hline & $\begin{array}{l}\square \text { Record the size and shape of each pupil (an irregularly shaped pupil, especially a teardrop should raise concern about } \\
\text { an anterior penetrating injury to the eye) }\end{array}$ \\
\hline & $\square$ Reactivity to light (trace, sluggish, or brisk) \\
\hline & $\begin{array}{l}\square \text { Swinging light test: assess for relative afferent pupillary defect } \\
\text { - Afferent pupillary defect may suggest optic nerve or retinal injury }\end{array}$ \\
\hline \multicolumn{2}{|c|}{ Visual acuity } \\
\hline & $\begin{array}{l}\square \text { Snellen eye chart } \\
\text { - Finger counting (if Snellen eye chart not available) } \\
\text { - Hand motion (if unable to visualize finger counting) } \\
\text { - Light perception (if unable to visualize hand motion) } \\
\text { - Total blindness (no light perception recognized) }\end{array}$ \\
\hline \multicolumn{2}{|r|}{ Optic nerve function/color evaluation } \\
\hline & $\begin{array}{l}\square \text { Red color saturation: bright red object is presented to one eye at a time, if optic nerve has suffered injury, } \\
\text { ipsilateral color perception will be altered }\end{array}$ \\
\hline & $\square$ White light intensity: less sensitive than red color test. More useful if there has been trauma within the eye \\
\hline \multicolumn{2}{|c|}{ Motility } \\
\hline & $\square$ Eye movements in each of the six major gaze positions \\
\hline \multicolumn{2}{|c|}{ Visual field determination } \\
\hline & $\square$ Central and peripheral visual field determination \\
\hline \multicolumn{2}{|r|}{ Intraocular pressure measurement } \\
\hline & $\square$ Generally assessed by ophthalmologist \\
\hline & $\square$ Can perform a gross digital intraocular pressure test if concerned \\
\hline \multicolumn{2}{|c|}{ Fundus examination } \\
\hline & $\square$ Generally assessed by ophthalmologist \\
\hline
\end{tabular}

decompression remain controversial without clear evidence supporting the interventions. Therefore, it is important to discuss with patients and family members that surgical interventions may not significantly improve vision and can potentially worsen symptoms.

In patients with traumatic optic neuropathy, studies have shown that facial skeleton manipulation and fracture repair have no adverse effect on vision. However, in this patient population it is important to work closely with the ophthalmology service to obtain surgical clearance. The majority of facial fractures do not necessitate immediate repair; therefore, in certain situations it may be helpful to wait until a more thorough evaluation and consent process can be performed. ${ }^{32,33}$

Formal ophthalmology consultation for adequate preoperative documentation of the vision status may be of benefit for patients with orbital injuries. It is unrealistic and unnecessary to do so in every patient with orbitozygomatic fracture. However, patients with extensive periorbital injuries (i.e., anterior skull base, frontal sinus, zygomaticomaxillary, NOE, and orbital floor fractures) warrant ophthalmology evaluation. As previously mentioned, it may be beneficial in select situations to delay orbital reconstruction until the appropriate assessments have been made.

Care should be taken when operating on a patient without a well-documented vision examination as this can expose the practitioner to a great deal of liability. Often in trauma scenarios patients are intubated, heavily sedated, or cognitively impaired which can lead to an incomplete ophthalmologic evaluation. In such situations, involvement of the ophthalmology service may be helpful for further evaluation and documentation purposes (-Table $\mathbf{3}$ ).

As a surgeon, knowing when to operative and when to medically manage is a difficult skillset to perfect. It can be difficult to proceed with surgery knowing worsening vision or blindness is a potential risk from surgical manipulations. Therefore, it is essential to understand the indications for immediate versus early surgical intervention for orbital floor fractures (-Table 5). In situations where patients present with relative contraindications, senior authors recommend staged orbital reconstruction (-Table 6). Due to 
662 Medicolegal Aspects of Craniofacial Trauma Vahidi et al.

Table 4 Facial examination for trauma evaluation

\begin{tabular}{|c|c|}
\hline \multicolumn{2}{|r|}{ Head and neck examination in facial trauma } \\
\hline \multicolumn{2}{|c|}{ Neurologic examination } \\
\hline & $\square$ Glasgow Coma Scale (GCS)-eye, verbal, motor \\
\hline & $\square$ Cervical spine evaluation \\
\hline & $\square$ Assess for any cerebrospinal (CSF) leakage \\
\hline & $\square$ Cranial nerve examination II-XII \\
\hline \multicolumn{2}{|c|}{ Head/face } \\
\hline & $\square$ Inspect the scalp and face, palpating bony landmarks, documenting any tenderness, step offs, or obvious deformities \\
\hline \multicolumn{2}{|r|}{$\begin{array}{l}\square \text { Examine soft tissue for lacerations or abrasions } \\
\text { - Lacerations to the cheek region should raise concern for parotid duct and facial nerve injury }\end{array}$} \\
\hline \multicolumn{2}{|r|}{$\square$ Sensory examination of the face (V1-3 distribution) } \\
\hline \multicolumn{2}{|r|}{$\square$ Assess facial symmetry (House-Brackmann Scale I-VI) } \\
\hline \multicolumn{2}{|c|}{ Eyes } \\
\hline \multicolumn{2}{|r|}{\begin{tabular}{|l}
$\square$ External examination (eyelid, periorbital swelling) \\
- Medial or lateral canthus position (normal intercanthal distance =35 mm)
\end{tabular}} \\
\hline \multicolumn{2}{|r|}{$\square$ Pupil evaluation (size, shape, reactivity to light) } \\
\hline \multicolumn{2}{|r|}{$\square$ Visual (color, finger counting, light perception, total blindness) } \\
\hline \multicolumn{2}{|r|}{$\square$ Motility-eye movement in each of the 6 major gaze positions } \\
\hline \multicolumn{2}{|r|}{$\square$ Penlight examination (assess conjunctiva, cornea, anterior chamber, lens) } \\
\hline \multicolumn{2}{|r|}{$\square$ Ophthalmology consult (intraocular pressure measurement, fundus examination) } \\
\hline \multicolumn{2}{|c|}{ Ears } \\
\hline \multicolumn{2}{|r|}{$\square$ Inspect external ear (size, shape, lacerations, hematoma) } \\
\hline \multicolumn{2}{|r|}{$\square$ Evaluate external auditory canal (otorrhea, swelling, bleeding, foreign body) } \\
\hline \multicolumn{2}{|r|}{$\square$ Evaluation of tympanic membrane (TM perforation, hemotympanum) } \\
\hline \multicolumn{2}{|r|}{$\square$ Weber and Rinne test } \\
\hline \multicolumn{2}{|c|}{ Nose } \\
\hline \multicolumn{2}{|r|}{$\square$ Evaluation of the external structure, inspect for swelling or asymmetry } \\
\hline \multicolumn{2}{|r|}{$\square$ Palpation of the nasal bridge for tenderness, crepitus, movement } \\
\hline & $\square$ Intranasal examination (rule out septal hematomas, septal perforations, epistaxis, foreign body) \\
\hline \multicolumn{2}{|c|}{ Throat/oral } \\
\hline \multicolumn{2}{|r|}{$\square$ Evaluation of occlusion (Class I, II, III) } \\
\hline \multicolumn{2}{|r|}{$\square$ Palate mobility-grasp the maxillary teeth and attempt to move the palate anteriorly while stabilizing the head } \\
\hline \multicolumn{2}{|r|}{$\square$ Evaluation of teeth, gingival and buccal mucosa, lips, floor of mouth, tongue, hard and soft palate } \\
\hline \multicolumn{2}{|r|}{$\square$ Look for open fractures, asymmetries, hematoma, lacerations, foreign bodies, avulsed, luxated teeth } \\
\hline \multicolumn{2}{|c|}{ Neck } \\
\hline \multicolumn{2}{|r|}{$\begin{array}{l}\text { Palpate anterior neck } \\
\text { - Crepitus in the neck may suggest laryngeal trauma, esophageal perforation, or pneumothorax } \\
\text { - Enlarging neck mass may suggest great vessel injuries or hematoma } \\
\text { - Carotid bruit may suggest carotid artery dissection/injury }\end{array}$} \\
\hline & $\square$ Examine for signs of penetrating neck injury or laceration \\
\hline
\end{tabular}

the risk of worsening vision, it is generally wise to defer orbital reconstruction and avoid orbital manipulation during facial fracture repair in patients with relative or absolute contraindications to reconstruction. Additionally, in this patient population it is important to work closely with the ophthalmology service to obtain surgical clearance (-Tables 5 and 6). ${ }^{33,34}$

\section{Emergency Medical Treatment and Active Labor Act Law}

Emergency Medical Treatment and Active Labor Act (EMTALA) is a federal law that was first enacted in 1986 and required that hospitals screen all patients who seek emergency care and stabilize or transfer those with medical 
Table 5 Indications for immediate versus early orbital reconstruction

\begin{tabular}{|c|c|}
\hline \multicolumn{2}{|l|}{ Indications for immediate orbital reconstruction } \\
\hline & $\begin{array}{l}\text { - Nonresolving oculocardiac reflex with entrapment } \\
\text { (especially in pediatrics) }\end{array}$ \\
\hline $\begin{array}{l}\text { - "White-eye" (no subconjunctival hemorrhage) } \\
\text { orbital floor fracture with entrapment }\end{array}$ \\
\hline Indications for early orbital reconstruction \\
\hline $\begin{array}{l}\text { - Symptomatic diplopia with muscle entrapment } \\
\text { as evidenced by positive forced duction test }\end{array}$ \\
\hline $\begin{array}{l}\text { - Large floor fracture that may cause latent } \\
\text { enophthalmos/hypoglobus }\end{array}$ \\
hypoglobus with diplopia
\end{tabular}

Table 6 Relative and absolute contraindications to orbital reconstructive surgery

\begin{tabular}{|c|l|}
\hline \multicolumn{2}{|l|}{$\begin{array}{l}\text { Relative and absolute contraindications } \\
\text { to orbital reconstruction }\end{array}$} \\
\hline $\begin{array}{l}\text { Relative } \\
\text { contraindications }\end{array}$ & $\begin{array}{l}\text { Absolute } \\
\text { contraindications }\end{array}$ \\
\hline $\begin{array}{c}\text { - Orbital fracture in } \\
\text { only seeing eye }\end{array}$ & - Globe rupture \\
\hline $\begin{array}{c}\text { - Evolving retrobulbar } \\
\text { hematoma }\end{array}$ & - Hyphema \\
\hline & - Retinal detachment \\
\hline & $\begin{array}{l}\text { - Traumatic optic } \\
\text { neuropathy (controversial) }\end{array}$ \\
\hline
\end{tabular}

emergencies, regardless of their health insurance policy or ability to pay. For a facial trauma surgeon on call this means that they must appear within a "reasonable period of time" after being notified that their services are needed, and that the emergency department physician is unqualified to perform the necessary intervention. EMTALA law further states that a hospital may not avoid the examination process and transfer the patient directly to a physician's office off campus to satisfy the requirement. ${ }^{35}$

Facial trauma surgeons can create a good interdisciplinary relationship with the emergency department staff by outlining conditions appropriate for consultation and educating emergency practitioners on basic principles they can employ themselves. Typically, conditions that necessitate a facial trauma surgeon include wounds that require skin grafting or flap reconstruction for coverage. Wounds that require a layered closure or involve nerves, vessels, and/or tendons, and lacerations involving the eyelid, periorbital region, lip, nasal mucosa or cartilage, or ear cartilage may warrant consultation of a facial trauma surgeon. Additionally, the request of a patient or family member for a facial plastic surgeon alone is not an appropriate indication for consultation of a surgeon. ${ }^{36}$

\section{Avoiding Unnecessary Litigation}

In nearly all circumstances, failures in communication or proper documentation may ultimately increase the risk of lawsuits. With regard to communication, it is important that medical providers begin managing patient expectations at the initial patient encounter. The discussion needs to include several components (1) the nature of the patient's condition, (2) the nature of the medical procedure and the potential benefits and realistic risks involved in the surgery, and (3) the limitations of modern medicine even when practiced at this highest level. Medical providers' difficulty with effective communication can open their practice up to a significant malpractice risk. The second component is proper documentation of the discussion, the potential risks involved throughout the treatment process, as well as documenting significant physical examination findings. ${ }^{37}$

\section{Statute of Limitations}

A statute of limitations is an important principle for medical providers to understand. It is a state law that sets a limit of time you have to file a lawsuit after you have suffered an injury and varies between states. Medical malpractice claims in Virginia for instance have a 2-year statute of limitations, which is the period within a plaintiff must file a lawsuit. The 2-year time period typically begins from the date of the original treatment, for a surgical patient that would be their operative date. There are several situations that can adjust the 2-year limitation. ${ }^{38}$ Sending a notice letter for instance can extend the 2-year limitation for an additional 75 days.

Another important exception is the "discovery rule" which states that if a plaintiff is unable to discover the basis of the lawsuit, investigate it, and file a lawsuit within 2 years, the plaintiff can file a suit within a reasonable amount of time after discovering the basis of the suit. This principle often becomes important when discussing retained surgical equipment, which can be discovered many years after the fact. It is, however, subject to a cap of 10 years from the date of injury in the state of Virginia. The statute of limitations for children is also more flexible; if a child under the age of 8 years of age is the victim of medical malpractice that child has until his or her 10th birthday to file a lawsuit. There are also differences in state malpractice policies when comparing state-employed medical providers and those in private practice. These are again unique to each state and therefore it is important for medical providers to review and understand their individual state malpractice policies. ${ }^{39-41}$

\section{Preparing for a Malpractice Case}

Although the goal is ultimately to provide effective highquality care, lawsuits may still happen despite the medical provider's best efforts. Since the majority of malpractice cases are resolved prior to trial as mentioned earlier, the deposition affords medical providers the best opportunity to directly influence the outcome of the case. 
The deposition process involves taking a sworn, out-ofcourt testimony for later use at trial. The purpose of this process is to obtain information from the witness and determine what the individual knows or remembers regarding the case in question. The plaintiffs' attorney will want to evaluate the ability and credibility of the physician as a witness. During this process the majority of the questioning will be done by the plaintiffs' attorney. It is important as the defendant in this process to project professional confidence, competence, and compassion as the plaintiff's attorney will be evaluating whether a jury would be favorably or unfavorably impressed by your testimony. ${ }^{42}$

As a defendant in a medical malpractice lawsuit it is extremely important to review and be well versed in the case in question. There are some general questions a medical provider can expect during the deposition or trial process. These include the following:

1. Description of the chronological order of events in the case.

2. A detailed description of the informed consent process.

3. How the decision was made to proceed with specific treatment plan, and what other treatment options were available.

4. Identification of all individuals directly responsible for the treatment and care of the patient.

5. Discussions of the surgical procedure should include the primary objective, prior outcomes, key technical aspects of the surgery, risk and potential complications, and possible alternatives to the surgery.

6. Questions may also be directed toward the personal and professional background of the provider, including questions regarding their education, licensure, board certifications, teaching responsibilities, and previous claims and lawsuits.

There are common mistakes that should be avoided as the defendant in medical malpractice lawsuit. As the defendant, it is important to avoid guessing or speculating on matters and volunteering information beyond the scope of a question. As a witness, discussing matters outside your area of expertise can cause greater harm than good. In addition, it would be helpful for the physician to be aware of the current standard of care so that one can intelligently defend oneself if there was a seeming deviation from the current standard. It is important that if asked, one can clearly express why such medical decision was made in a logical, clear fashion based on factors that were considered at the time along with potential risks, benefits, and alternative treatment options that were also discussed with the patient. Lastly, just like in medicine, ultimately the best thing a defendant can do is to prepare by reviewing charts and relevant information involving the case. ${ }^{42}$

\section{Conclusion}

Craniofacial trauma surgeons have a unique opportunity to help patients recover from a traumatic event and save them from lifelong cosmetic disfigurement or significant functional impairment. Due to the time-sensitive nature involving trauma-related injuries, it is imperative to know when immediate surgical intervention should be given and when a delayed course of action is more appropriate. Careful, timely documentation of abnormal findings and detailed discussion of potential complications during the informed consent process may increase the possibility of avoiding malpractice lawsuits or having them resolve successfully in the physician's favor.

Surgical complications involving the facial nerve with resulting facial paralysis or the optic nerve with resulting vision loss have been found to be associated with increased risk of litigation. Therefore, if relevant to surgery, the risks of $\mathrm{CN}$ injuries should be mentioned. If a surgical complication or suboptimal surgical outcome has occurred, open communication and transparency with the patient and family is important ethically and will likely minimize risk of lawsuit.

All practicing clinicians should be familiar with EMTALA expectations as well as individual state laws regarding the statute of limitation. Although being involved in a malpractice lawsuit can be devastating as a clinician who provides medical care with integrity and good intent, it is important to remember most malpractice claims are decided in the physician's favor. It is important as a practitioner in the medical field to seek out experienced malpractice attorneys that can guide you through the process.

\section{Conflicts of Interest}

None declared.

\section{References}

1 Jena $A B$, Seabury S, Lakdawalla D, Chandra A. Malpractice risk according to physician specialty. N Engl J Med 2011;365(07): 629-636

2 Studdert DM, Mello MM, Gawande AA, et al. Claims, errors, and compensation payments in medical malpractice litigation. $\mathrm{N}$ Engl J Med 2006;354(19):2024-2033

3 Svider PF, Keeley BR, Zumba O, Mauro AC, Setzen M, Eloy JA. From the operating room to the courtroom: a comprehensive characterization of litigation related to facial plastic surgery procedures. Laryngoscope 2013;123(08):1849-1853

4 McGwin G Jr, Wilson SL, Bailes J, Pritchett P, Rue LW III. Malpractice risk: trauma care versus other surgical and medical specialties. JTrauma 2008;64(03):607-612, discussion 612-613

5 Stewart RM, Corneille MG, Johnston J, et al. Transparent and open discussion of errors does not increase malpractice risk in trauma patients. Ann Surg 2006;243(05):645-649, discussion 649-651

6 Esposito TJ, Maier RV, Rivara FP, Carrico CJ. Why surgeons prefer not to care for trauma patients. Arch Surg 1991;126(03):292-297

7 Chan Y, Irish JC, Wood SJ, et al. Patient education and informed consent in head and neck surgery. Arch Otolaryngol Head Neck Surg 2002;128(11):1269-1274

8 Sivanadarajah N, El-Daly I, Mamarelis G, Sohail MZ, Bates P. Informed consent and the readability of the written consent form. Ann R Coll Surg Engl 2017;99(08):645-649

9 Silberstein E, Shir-Az O, Reuveni H, et al. Defensive medicine among plastic and aesthetic surgeons in Israel. Aesthet Surg J 2016;36(10):NP299-NP304

10 Stewart RM, Johnston J, Geoghegan K, et al. Trauma surgery malpractice risk: perception versus reality. Ann Surg 2005;241 (06):969-975, discussion 975-977

11 Svider PF, Sunaryo PL, Keeley BR, Kovalerchik O, Mauro AC, Eloy JA. Characterizing liability for cranial nerve injuries: a detailed analysis of 209 malpractice trials. Laryngoscope 2013;123(05):1156-1162 
12 Therattil PJ, Chung S, Sood A, Granick MS, Lee ES. An analysis of malpractice litigation and expert witnesses in plastic surgery. Eplasty 2017;17:e30

13 De Brauwer F, Bertolus C, Goudot P, Chaine A. Causes for litigation and risk management in facial surgery: a review of 136 cases. J Stomatol Oral Maxillofac Surg 2018:S2468-7855(18)30274-X

14 Rayess HM, Svider PF, Hanba C, et al. A cross-sectional analysis of adverse events and litigation for injectable fillers. JAMA Facial Plast Surg 2018;20(03):207-214

15 Piras M, Delbon P, Conti A, et al. Cosmetic surgery: medicolegal considerations. Open Med (Wars) 2016;11(01):327-329

16 Rayess HM, Svider P, Hanba C, Patel VS, Carron M, Zuliani G. Adverse events in facial implant surgery and sssociated malpractice litigation. JAMA Facial Plast Surg 2018;20(03):244-248

17 Tung TC, Tseng WS, Chen CT, Lai JP, Chen YR. Acute life-threatening injuries in facial fracture patients: a review of 1,025 patients. J Trauma 2000;49(03):420-424

18 Lee TS, Ducic Y, Gordin E, Stroman D. Management of carotid artery trauma. Craniomaxillofac Trauma Reconstr 2014;7(03): 175-189

19 Mulligan RP, Friedman JA, Mahabir RC. A nationwide review of the associations among cervical spine injuries, head injuries, and facial fractures. JTrauma 2010;68(03):587-592

20 Kraus RR, Bergstein JM, DeBord JR. Diagnosis, treatment, and outcome of blunt carotid arterial injuries. Am J Surg 1999;178 (03):190-193

21 Dua A, Desai SS, Kuy S, et al. Predicting outcomes using the National Trauma Data Bank: optimum management of traumatic blunt carotid and blunt thoracic injury. Perspect Vasc Surg Endovasc Ther 2012;24(03):123-127

22 Schneidereit NP, Simons R, Nicolaou S, et al. Utility of screening for blunt vascular neck injuries with computed tomographic angiography. J Trauma 2006;60(01):209-215, discussion 215-216

23 Cogbill TH, Moore EE, Meissner M, et al. The spectrum of blunt injury to the carotid artery: a multicenter perspective. JTrauma 1994;37(03):473-479

24 Gordin E, Lee TS, Ducic Y, Arnaoutakis D. Facial nerve trauma: evaluation and considerations in management. Craniomaxillofac Trauma Reconstr 2015;8(01):1-13

25 Mundinger GS, Borsuk DE, Okhah Z, et al. Antibiotics and facial fractures: evidence-based recommendations compared with experience-based practice. Craniomaxillofac Trauma Reconstr 2015;8(01):64-78
26 Morris LM, Kellman RM. Complications in facial trauma. Facial Plast Surg Clin North Am 2013;21(04):605-617

27 Soparkar CN, Patrinely JR. The eye examination in facial trauma for the plastic surgeon. Plast Reconstr Surg 2007;120(07, Suppl 2):49S-56S

28 Amrith S, Saw SM, Lim TC, Lee TK. Ophthalmic involvement in cranio-facial trauma. J Craniomaxillofac Surg 2000;28(03):140-147

29 Ord RA. Post-operative retrobulbar haemorrhage and blindness complicating trauma surgery. Br J Oral Surg 1981;19(03): 202-207

30 Lessell S. Indirect optic nerve trauma. Arch Ophthalmol 1989;107 (03):382-386

31 Levin LA, Beck RW, Joseph MP, Seiff S, Kraker R. The treatment of traumatic optic neuropathy: the International Optic Nerve Trauma Study. Ophthalmology 1999;106(07):1268-1277

32 Wang BH, Robertson BC, Girotto JA, et al. Traumatic optic neuropathy: a review of 61 patients. Plast Reconstr Surg 2001;107(07): 1655-1664

33 Hsieh CH, Kuo YR, Hung HC, Tsai HH, Jeng SF. Indirect traumatic optic neuropathy complicated with periorbital facial bone fracture. JTrauma 2004;56(04):795-801

34 Shibuya TY, Feinberg SM, Mathog RH, et al. Visual risks of facial fracture repair in the setting of traumatic optic neuropathy. Arch Otolaryngol Head Neck Surg 2006;132(03):258-264

35 McKenna RM, Purtle J, Nelson KL, Roby DH, Regenstein M, Ortega AN. Examining EMTALA in the era of the patient protection and Affordable Care Act. AIMS Public Health 2018;5(04):366-377

36 Smoot EC. EMTALA laws and the plastic surgeon in the emergency department. Plast Reconstr Surg 2002;109(07):2603-2604

37 Yankowsky KW. Avoiding unnecessary litigation: communication and documentation. Adv Skin Wound Care 2017;30(02):66-70

38 Lillich RB. Malpractice statute of limitations in New York and other jurisdictions. Cornell Law Quarterly 1962;3(47):339-373

39 Goodma ML, Freeman-Jones K, McCauley KM. Annual survey of Virginia Law: damages for medical malpractice in Virginia. Univ Richmond Law Rev 1999;33(03):919-937

40 Lorenzen EG. The statute of limitations and the conflict of laws. Yale Law J 1919;28(05):492-498

41 Danzon P. The frequency and severity of medical malpractice claims. J Law Econ 1984;27(01):115-148

42 Kedarnath NS, Shruthi R. Maxillofacial surgeon as fact witness for medico-legal cases: Indian scenario. J Maxillofac Oral Surg 2015; 14(04):962-971 